\title{
LAS PINTURAS DEL RETABLO MAYOR DE SABIÑÁN (ZARAGOZA): APORTACIÓN AL CATÁLOGO CRÍTICO DE OBRAS DE JUSEPE MARTÍNEZ, PINTOR DE FELIPE IV*
}

\author{
Rebeca Carretero Calvo ${ }^{1}$ \\ Universidad de Zaragoza
}

\begin{abstract}
Este artículo da a conocer, documenta y analiza las pinturas del retablo mayor de la iglesia de San Pedro de la localidad zaragozana de Sabiñán, ejecutadas por el aragonés Jusepe Martínez, pintor del rey ad honorem, en 1653. Asimismo, se establecen los modelos iconográficos en los que se pudo basar para crear estas composiciones. El estudio detallado de estos lienzos pone de relieve las características de la producción artística de Martínez, a caballo entre el clasicismo, aprendido de Guido Reni y Domenichino durante su estancia romana, y el naturalismo de raíz caravaggiesca, por lo que se convierten en una magnífica muestra de la influencia del arte italiano en la pintura aragonesa.
\end{abstract}

Palabras clave: Jusepe Martínez; Sabiñán; siglo XVII; pintura; Aragón; Italia.

\section{THE PAINTINGS OF THE MAIN ALTARPIECE AT SABIÑÁN (ZARAGOZA): AN ADDITION TO THE CATALOG OF WORKS BY JUSEPE MARTÍNEZ, PAINTER OF PHILIP IV}

This article details, documents, and analyzes the paintings of the main altarpiece of the church of Saint Peter in Sabiñán, completed in 1653 by the Aragonese artist Jusepe Martínez, court painter ad honorem. It also explores the iconographic models on which the artist likely based the composition. A detailed study of these canvases highlights the characteristics of Martínez artistic production, which straddled classicism, learned from Guido Reni and Domenichino during his Roman stay, and Caravaggio's naturalism. Jusepe Martínez embodies the influence of Italian art on Aragonese painting.

Key words: Jusepe Martínez; Sabiñán; 17th century; painting; Aragon; Italy.

Cómo citar este artículo / Citation: Carretero Calvo, Rebeca (2021) "Las pinturas del retablo mayor de Sabiñán (Zaragoza): aportación al catálogo crítico de obras de Jusepe Martínez, pintor de Felipe IV”. En: Archivo Español de Arte, vol. 94, núm. 374, Madrid, pp. 117-132. https://doi.org/10.3989/aearte.2021.07

Jusepe Martínez (1600-1682) es, sin lugar a dudas, el pintor aragonés más relevante del siglo XVII. Aunque han sido varios los autores que se han dedicado al estudio de su figura, su producción pictórica conservada — que no documentada - es escasa, reduciéndose sobre todo a cuadros devocionales y lienzos para retablos 2 . No obstante, la labor de archivo ha revelado que todavía pueden salir a la luz nuevas obras de este artista. Así, en este texto damos a conocer las pinturas

\footnotetext{
* Este trabajo se ha realizado en el marco del Grupo de investigación de referencia Vestigium (H19_20R), financiado por el Departamento de Ciencia, Universidad y Sociedad del conocimiento del Gobierno de Aragón (2020-2022).

${ }^{1}$ rcc@unizar.es / ORCID iD: https://orcid.org/0000-0002-1754-1597

${ }^{2}$ Como se pone de relieve en Martínez, 2008: X-XI.
} 
del retablo mayor de la iglesia de San Pedro de Sabiñán (Zaragoza), localidad adscrita administrativamente a la Comarca Comunidad de Calatayud y eclesiásticamente a la diócesis de Tarazona, ejecutadas por Jusepe Martínez en $1653^{3}$.

Además de contextualizar y analizar este trabajo en relación con el resto de su producción, en las páginas que siguen buscaremos tanto los modelos empleados como las influencias recibidas para su creación, demostrando que el uso de grabados y el conocimiento directo del arte italiano constituyen dos constantes en su obra. Igualmente, trataremos de averiguar qué pudo estar detrás de la llegada de Martínez a esta población bilbilitana.

Jusepe Nicolás Martínez fue el tercer hijo del también pintor de origen flamenco Daniel Martínez (1555-1636), con el que probablemente se formó, y de Isabel Lurbez, natural de la localidad zaragozana de Ejea de los Caballeros, donde contrajeron matrimonio el 19 de junio de $1581^{4}$. En 1622 tuvo la oportunidad de viajar a Italia para concluir su aprendizaje y conocer de primera mano los frutos de la renovación artística alcanzada a comienzos del Seiscientos en Roma, ciudad en la que parece que permaneció hasta $1625^{5}$. No obstante, la primera vez que está documentado en Zaragoza después de su regreso es el 11 de diciembre de 1627, fecha en la que formaliza su enlace con Ana Francisca Jenequi, hija del platero napolitano afincado en la capital aragonesa Claudio Jenequi y de su esposa Juana Alexandre.

Probablemente gracias a la mediación de Diego Velázquez — al que conoció en su viaje a Madrid en 1634-, Martínez fue nombrado pintor ad honorem de Felipe IV el 8 de abril de 16447, momento en el que se encontraba en el punto más álgido de su carrera artística. El prestigio de Jusepe Martínez como pintor, sobre todo después de su nombramiento real, debía ser más que evidente en la capital aragonesa, razón por la que recibió multitud de encargos ${ }^{8}$. El Cabildo de la Seo de Zaragoza fue uno de sus principales promotores y para él llevó a cabo las pinturas para el retablo de la capilla de la Virgen Blanca, lugar de enterramiento de los arzobispos zaragozanos en la catedral, que ejecutó entre 1646 y $1647^{9}$; asimismo, participó en el proceso de beatificación del inquisidor Pedro Arbués, dinamizado a partir de 1648, realizando trabajos de expertizaje ${ }^{10}$. Además, en mayo de 1678 entregó a la Seo un lienzo con la representación del Salvador junto con "una lapida de porfido". El cabildo decidió colgarlo "en la capilla de Santo Dominguito o en la Sacristia" ${ }^{11}$. Sin embargo, hasta el momento esta obra no ha podido ser identificada. Igualmente, se le han atribuido la tela que preside la capilla de las Tres Santas Mártires ubicada en el trascoro y la Aparición de la Virgen a San Jacinto de la sala capitular ${ }^{12}$.

Su fama se extendió por todo el reino de Aragón y parroquias como la de Nuestra Señora de la Asunción de La Almunia de Doña Godina (Zaragoza) (h. 1647-1652) ${ }^{13}$ y Santa María de Uncastillo (Zaragoza) (1647-1649) ${ }^{14}$ requirieron sus servicios para que confeccionara las pinturas de

\footnotetext{
${ }^{3}$ Agradecemos a los investigadores Francisco Tobajas y José Luis Cortés su generosidad por darnos a conocer los dos documentos inéditos que constituyen la base de este trabajo, así como al profesor Jesús Criado sus atentas consideraciones y sugerencias. Igualmente, deseamos mostrar nuestro agradecimiento a Luisma García por las fotografías del retablo que ilustran este texto.

${ }^{4}$ González Hernández, 1981: 125 [doc. n. ${ }^{\circ}$ 1].

5 Manrique Ara, 2000: 18-19.

${ }^{6}$ La transcripción íntegra de la capitulación matrimonial se encuentra en Roy Lozano, 2006: 391-395 [doc. n. ${ }^{\circ}$ 5-7405 (8175)]. Disponible en línea en https:/ifc.dpz.es/recursos/publicaciones/26/14/_ebook.pdf [15 de abril de 2020].

7 Manrique Ara, 2002: 34.

8 González Hernández, 1981.

9 Lozano López, 2010: 71-72.

${ }^{10}$ Carretero Calvo, 2020: 242-244.

${ }_{11}$ Actas capitulares 1676-1680, cabildo ordinario de 13 de mayo de 1678, Archivo Capitular de la Seo de Zaragoza, p. 152.

${ }^{12}$ Lozano López, 2010: 72-74.

13 Ansón Navarro, 2002: 5-74. El profesor Ansón considera que los lienzos pudieron ser concluidos en 1651 o, como muy tarde, en 1652 (Ansón Navarro, 2002: 10). Véase asimismo Carreras / Núñez / Ripollés, 2010; y Manrique Ara, 2012: 300-306

${ }^{14}$ Manrique Ara, 2002: 29-183.
} 
sus retablos mayores. Por aquellos mismos años la basílica de San Lorenzo de Huesca le encargó el lienzo de La Virgen de Monserrat con los Santos Orencio, Paciencia y sus hijos San Lorenzo y San Orencio, obispo de Auch (h. 1645) ${ }^{15}$. A estas importantes obras realizadas fuera de la capital aragonesa debemos sumar ahora las pinturas para el retablo mayor de la iglesia parroquial de San Pedro de Sabiñán (1653), hasta la fecha totalmente desconocidas.

A todo ello, se debe añadir que Jusepe Martínez fue el encargado de educar artísticamente a don Juan José de Austria que, durante los años que permaneció en Zaragoza como virrey de Aragón (1669-1677), se convertirá en uno de sus protectores ${ }^{16}$. De hecho, a él le dedicó sus Discursos practicables del nobilísimo arte de la pintura, tratado escrito hacia $1675^{17}$. A esta obra acudiremos en repetidas ocasiones para profundizar de modo más adecuado en las pinturas que ahora presentamos, pues en su redacción Martínez combinó las noticias biográficas de diversos artífices - $\mathrm{y}$ también autobiográficas - con sus consideraciones artísticas.

\section{El retablo mayor de la parroquial de Sabiñán}

Gracias a las Notas para la historia de Sabiñán (1919) de José Gracián Gasca sabemos que a finales del siglo XVI la iglesia de San Pedro no tenía suficiente capacidad para albergar a toda la feligresía. Desde 1579 los sucesivos visitadores ordenaron la ampliación del templo, mandato que no se pudo cumplir por cuestiones económicas hasta $1625^{18}$. En efecto, el 17 de junio de 1625 los obreros de villa bilbilitanos Francisco de Aguirre, Miguel de Gromendadi y Juan de Segura fueron contratados para levantar la nueva iglesia por valor de 1.200 escudos $^{19}$. La fábrica fue bendecida el 31 de julio de $1627^{20}$, circunstancia que indica que los trabajos estarían muy avanzados. A comienzos de 1630 el edificio debía estar prácticamente ultimado, pues el 31 de enero de ese año el escultor Francisco del Condado y el pintor Francisco de Celaya recibieron un pago de 600 sueldos de manos del vicario de Sabiñán, probablemente por la realización de los tondos de madera policromada con la representación de los apóstoles que ornan las enjutas de los arcos de ingreso a las capillas y las lunetas del transepto, así como las efigies de los evangelistas acomodadas en las pechinas de la cúpula erigida sobre el crucero ${ }^{21}$.

Sin embargo, no disponemos de documentación acerca de la confección de la mazonería del retablo mayor. El hecho de que para 1630 se estuviera decorando el templo unido a las características del mueble - que sigue los rasgos de los retablos bilbilitanos fechados en la década de 1630 — $^{22}$, nos lleva a pensar que debería haber sido diseñado por esos años [fig. 1]. No obstante, merced a los datos que ahora manejamos, no fue dorado hasta 1652 y sus pinturas estaban siendo

\footnotetext{
15 Ansón Navarro, 1989: 7-11.

${ }^{16}$ González Asenjo, 2005.

17 Martínez, 2006. La doctora González Asenjo considera que el tratado de pintura de Martínez no llegó a publicarse inmediatamente después de su redacción porque "no se produjo la entrega del manuscrito a don Juan o fuera redactado en fechas posteriores a la presencia del príncipe en Zaragoza" (véase González Asenjo, 2005: 453; 2019: 501). No obstante, la doctora Manrique Ara discrepa de ello proponiendo la posibilidad de que Martínez prefiriera distribuir su texto en copias manuscritas debido a que lo escribió para "la elite cultural, que, desde luego, coincidía con la social" (en Martínez, 2008: XII-XVII).

${ }_{18}$ Gracián Gasca, 2013: 14-15. Disponible en línea en https://issuu.com/sabinius/docs/notas_historia_revisada_tobajas_201 [11 de abril de 2020].

19 Rubio Semper, 1980: 116-119 y 178-179 [docs. núms. 71 y 72].

${ }^{20}$ Gracián Gasca, 2013: 18.

${ }^{21}$ Rubio Semper, 1980: 119 y 186 [doc. n. ${ }^{\circ} 89$ ].

${ }^{22}$ Si bien no dispone de las triples columnas tan empleadas en esta zona durante esos años (Criado Mainar, 2013: 227-259). Lo que resulta muy significativo es la decoración del tercio del imoscapo de las columnas, con puntas de diamante. Las primeras de este tipo documentadas en tierras bilbilitanas son las del retablo de Torrijo de la Cañada, que ya estaba en pie en 1636. Es una solución que parece provenir de Castilla, pues el ensamblador de Torrijo, Pedro de Cicarte (1599-1666), era natural de El Burgo de Osma (Soria). Sobre el retablo de Torrijo véase Costa Florencia, 2017: 85-88.
} 


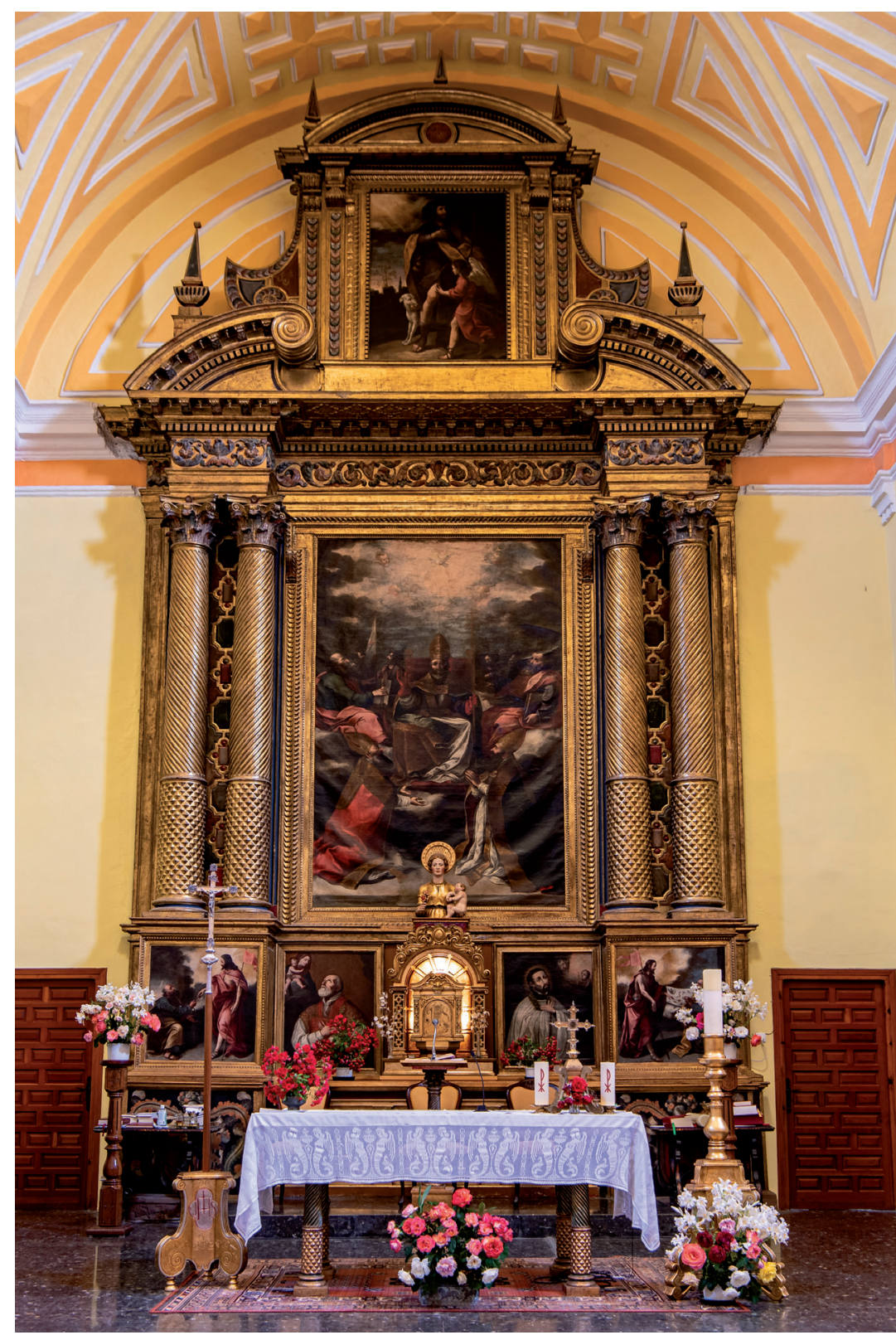

Fig. 1. Sabiñán, iglesia parroquial de San Pedro, retablo mayor (Fotog. Luisma García).

ejecutadas por Jusepe Martínez en 1653. Esto podría deberse a que, aunque la mazonería fuera realizada hacia 1635-1640, pudo mantenerse en blanco y presidida por una pintura provisional del apóstol San Pedro, titular del templo ${ }^{23}$, hasta 1652-1653.

En efecto, el 20 de diciembre de 1652 el dorador Juan Ortiz y Baraiz, habitante en la villa zaragozana de Brea, reconoció tener en comanda 8.000 sueldos jaqueses de la iglesia parroquial

${ }^{23}$ En 1919 en las dependencias de la parroquia se conservaban diversos cuadros, entre los que destaca una pintura "grande del Patrón de la parroquia, San Pedro Apóstol" que, según José Gracián, "debieron estar en los altares, antes de hacerse los retablos que hoy tenemos y en otros suprimidos" (Gracián Gasca, 2013: 22-23). Sin embargo, no hemos logrado localizar esta obra. 
de Sabiñán. ${ }^{24}$ Aunque el documento no concreta el trabajo a realizar — doc. n. ${ }^{\circ} 1-$, la cantidad económica estipulada no ofrece dudas de que se trata del dorado y policromado del retablo mayor del templo.

Juan Ortiz y Baraiz, igual que su hermano Felipe ${ }^{25}$, era un pintor dorador, documentado como vecino de Calatayud en 1641 y $1642^{26}$. En esos años estaba llevando a cabo el dorado de un retablo - sin determinar en los albaranes de pago - en la iglesia parroquial de Fuentes de Jiloca (Zaragoza) ${ }^{27}$. La siguiente mención localizada acerca de este artífice es la que ahora presentamos situándolo en Sabiñán para ejecutar la policromía del retablo mayor de San Pedro en 1652. El hecho de que en ese momento se le consigne como habitante en Brea de Aragón sugiere que debió ser él el encargado de dorar el retablo mayor de la iglesia de Santa Ana. Esta suposición no resulta en absoluto descabellada, pues 1652 es el año que se registra en uno de los escudos del cabildo del Pilar de Zaragoza, comitente de la obra, tallados en el sotabanco del propio mueble ${ }^{28}$.

Y, para finalizar, el 25 de marzo de 1653 el pintor zaragozano Jusepe Martínez se desplazó hasta Sabiñán para otorgar ante notario haber recibido 5.000 sueldos jaqueses y doce arrobas de aceite de parte de la iglesia parroquial de San Pedro y del concejo de la localidad, y 800 sueldos más "por aber benido a concertar la obra i traella" — doc. n. ${ }^{\circ} 2-29$.

\section{Las pinturas del retablo}

El retablo mayor de San Pedro es un mueble de pintura compuesto de sotabanco, banco, cuerpo de una sola calle y ático de una casa. El sotabanco avanza en los extremos al nivel de los soportes del cuerpo en cuyos frentes campean pintadas directamente sobre la tabla las armas del capítulo eclesiástico de San Pedro apóstol de Sabiñán. El banco se retranquea en el centro y está presidido por un sagrario de factura moderna rematado por un busto de la Virgen con el Niño, que puede ser datado hacia $1560^{30}$. A ambos lados se sitúan dos lienzos enmarcados con la representación de la Visión de San Felipe Neri, a la izquierda — desde el punto de vista del espectador —, y de San Francisco Javier, a la derecha. Como sucedía en el sotabanco, los laterales de la predela se adelantan para actuar como netos de los soportes del cuerpo. En sus frentes aparecen la Entrega de las llaves a San Pedro y El sueño de San Pedro.

El cuerpo está ocupado por una pintura sobre tela de grandes dimensiones con el tema de San Pedro en cátedra rodeada por un marco con orejas decorado con gallones y dentellones, y flanqueada por parejas de columnas de fuste entorchado con puntas de diamante al tercio del imoscapo y capitel de orden corintio. Estas disponen de retropilastras ornadas con motivos geométricos de raíz serliana y sustentan un friso con roleos acantiformes en relieve.

Un frontón curvo partido y avolutado da paso a la casa del ático en la que se incluye una pintura de San Roque con el ángel, patrón de la localidad, con un marco de características similares al del lienzo titular. Parejas de pilastras ganchudas sostienen el frontón curvo rematado con tres

${ }^{24}$ Protocolo de Miguel García Guerrero, notario de Sabiñán, 20 de diciembre de 1652, Archivo Histórico de Protocolos Notariales de Calatayud (A.H.P.C.), libro 1437, f. 129.

${ }^{25}$ Felipe Ortiz de Baraiz perteneció al gremio de doradores de Zaragoza al menos entre 1678 y 1683 (Ansón Navarro, 1987: 497). Véanse igualmente los datos biográficos recogidos en Boloqui Larraya, 1983 (vol. I): 191.

${ }^{26}$ Rubio Semper, 1980: 77.

${ }^{27}$ El profesor Rubio Semper lo identifica con el mueble dedicado a Nuestra Señora del Rosario (en Rubio Semper, 1980: 77, 242 y 244 [docs. núms. 169 y 174, respectivamente]). Pero en realidad debe relacionarse con la factura del retablo mayor de dicho templo. El error se enmienda en Criado Mainar, 2011: 27-28; y en 2013a: 198 y 234-237. Sobre el último mueble citado véase Carretero Calvo, 2007: 29-89.

${ }^{28}$ Cortés Perruca, 2019: 137-138.

29 Protocolo de Miguel García Guerrero, notario de Sabiñán, 25 de marzo de 1653, A.H.P.C., libro 1438, f. 30 v.

${ }^{30}$ Esta pieza presenta evidentes concomitancias con el busto de Santa Afra de la iglesia de Nuestra Señora de los Ángeles de Villalengua (Zaragoza), de autor desconocido. Véase Lacarta Aparicio / García-Aráez / Menéndez Zapata, 2010: 78-103; y Criado Mainar, 2014: 351-352. 


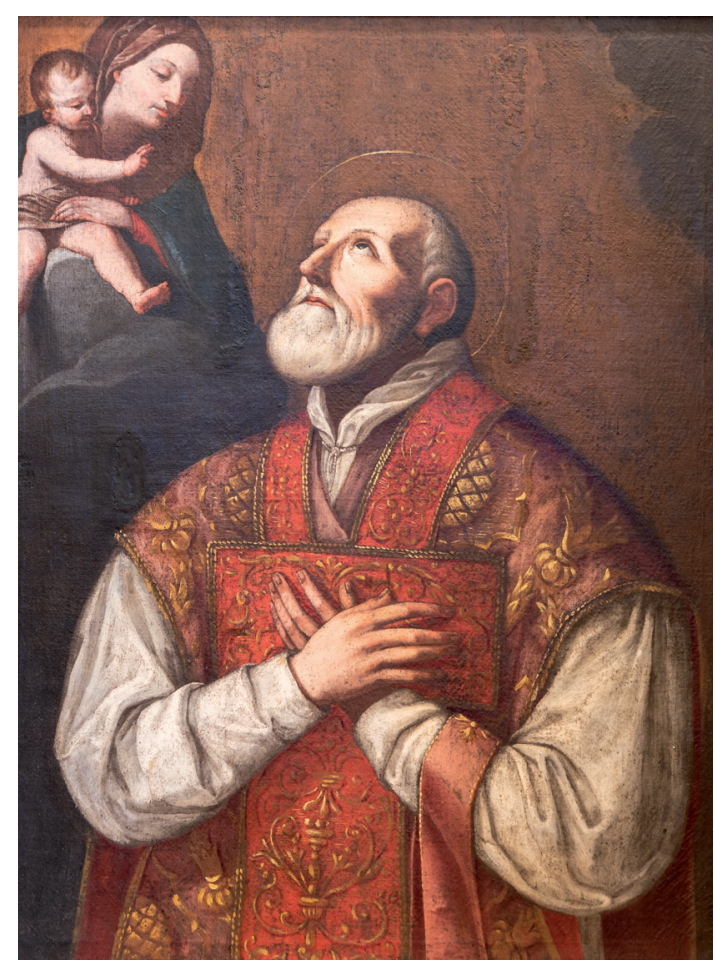

Fig. 2. Jusepe Martínez, Visión de San Felipe Neri, 1653. Sabiñán, iglesia parroquial de San Pedro, retablo mayor (Fotog. Luisma García).

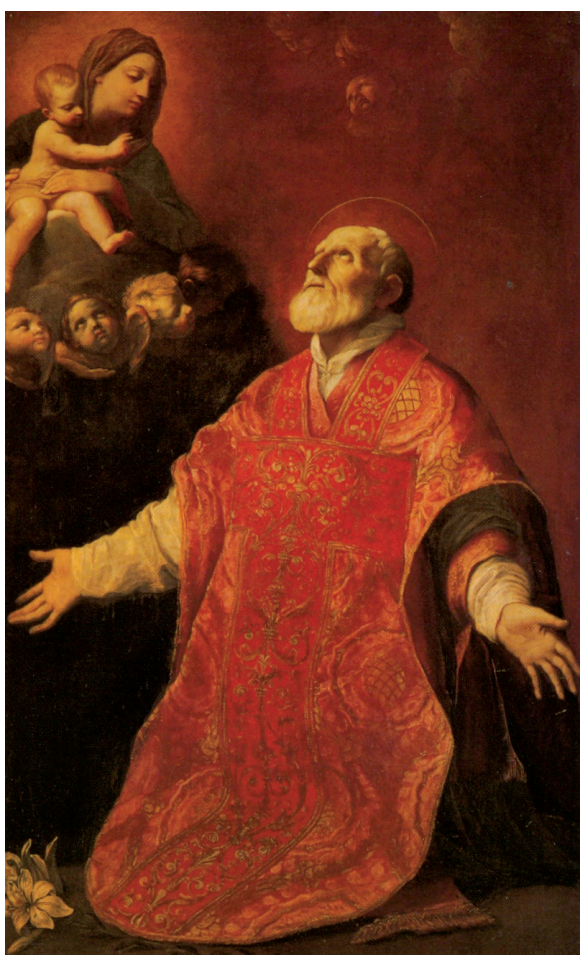

Fig. 3. Guido Reni, Visión de San Felipe Neri, 1614. Roma, Chiesa Nuova.

pirámides que corona el conjunto. Este mueble fue restaurado en 1999 por Concha Domínguez y Óscar Oliva a instancias de la Diputación Provincial de Zaragoza y el Ayuntamiento de Sabiñán.

Las seis telas mencionadas incluidas en la mazonería se deben a los pinceles de Jusepe Martínez. Todas ellas muestran las características de la obra del zaragozano y, lo que resulta aún más interesante, la mayor parte presenta deudas con su producción anterior, con pinturas de artistas italianos - o afincados en Italia en algún momento - o con grabados. No obstante, las representaciones de San Felipe Neri y San Francisco Javier parecen de factura más dura, por lo que podrían tratarse de obras de taller.

Comenzaremos justamente por ellas para aproximarnos a las fuentes en las que Martínez bebió para componer los lienzos sabiñaneros. En primer lugar, para la Visión de San Felipe Neri [fig. 2] siguió con bastante precisión la pintura homónima que Guido Reni llevó a cabo en 1614 para la Chiesa Nueva de Roma [fig. 3] ${ }^{31}$. No obstante, tuvo que reducir el formato de la composición para adecuarlo al espacio arquitectónico del banco del retablo, por lo que, en lugar de mostrar al santo de cuerpo entero lo representa de busto. Este cambio llevó al pintor zaragozano a cruzar las manos del religioso delante del pecho en vez de extender sus brazos. Asimismo, sintetizó la aparición de María y el Niño prescindiendo de los querubines que rodean la nube sobre la que se disponen en la obra romana.

Según el propio testimonio de Jusepe Martínez, sabemos que conoció a "dos famosos pintores de Roma a quienes comuniqué mucho, que fueron el insigne Guido Reni y el otro el estudioso

${ }^{31}$ Es preciso advertir que hace tiempo se abrió un debate acerca de si Jusepe Martínez se sirvió de la estampa de Juan de Noort fechada en 1651 reproduciendo la obra reniana o partió de su conocimiento directo de la obra romana (véase Manrique Ara, 2002: 61-63). Nosotros defendemos la segunda postura debido a la gran fidelidad que muestran las copias de Martínez con respecto a la pintura de Reni que no se encuentran en el grabado de Noort, de manera particular en la figura de la Virgen y el Niño. 


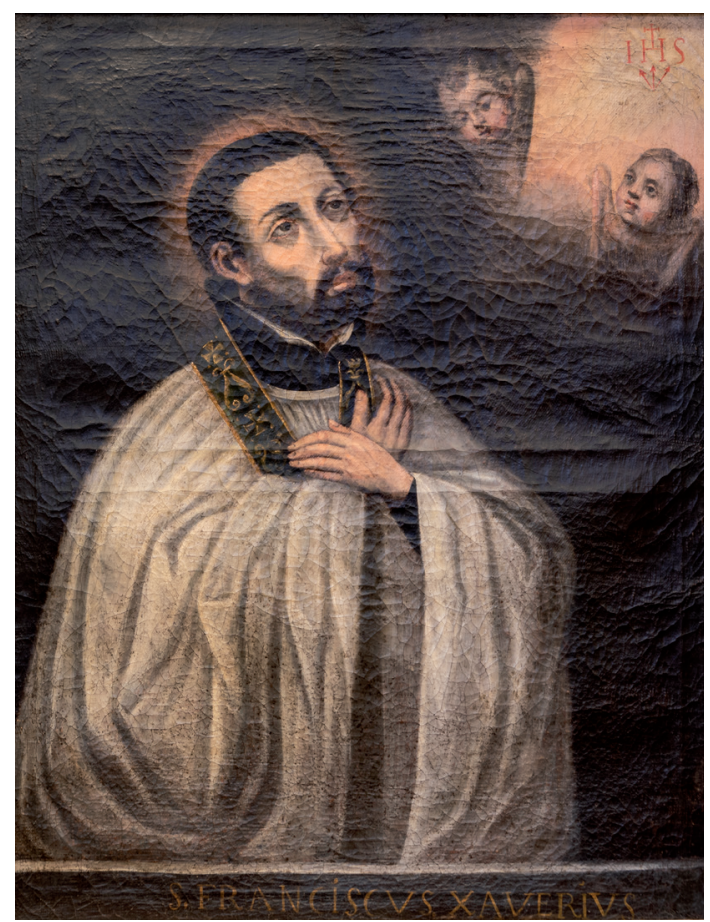

Fig. 4. Jusepe Martínez, San Francisco Javier, 1653.

Sabiñán, iglesia parroquial de San Pedro, retablo mayor (Fotog. Luisma García).

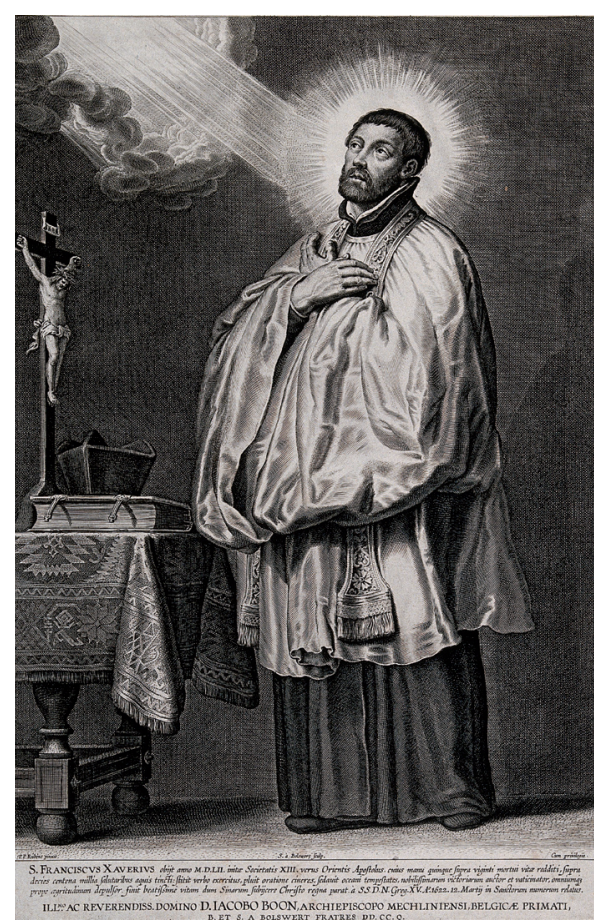

Fig. 5. San Francisco Javier, grabado de Schelte Adams à Bolswert según composición de Rubens, h. 1622. (C) The Trustees of the British Museum, $1871,1209.2396$.

Domenichino" ${ }^{32}$. Incluso es posible que completara su formación en la Ciudad Eterna dedicándose a reproducir obras devotas, como el San Felipe Neri de Reni. ${ }^{33}$ De hecho, aparte de esta de Sabiñán, Martínez ejecutó otras réplicas de esta pintura, como la conservada en la iglesia de San Miguel de los Navarros de Zaragoza, parroquia en la que fue enterrado en $1682^{34}$.

Por su parte, para la pintura de San Francisco Javier [fig. 4] tomó como modelo la obra de Pedro Pablo Rubens del mismo tema ejecutada en 1616 para la iglesia de la Compañía de Jesús de Bruselas, pero que quizá estuvo - junto con la representación de San Ignacio de Loyola también del flamenco - en el Gesù de Roma antes de viajar a la capital belga ${ }^{35}$. Esta obra fue grabada por Schelte Adams à Bolswert después de la canonización de ambos en 1622 [fig. 5].

Como sucediera en la tela de San Felipe Neri, Martínez adecuó de nuevo el formato de la pintura al espacio de la predela representando al santo de medio cuerpo. Por lo demás, siguió con bastante similitud la composición rubensiana, si bien la presencia de los dos querubines y el emblema de la Compañía de Jesús en el rompimiento de gloria lleva a plantear la posibilidad de que la fuente fuera el grabado que, partiendo de Rubens, abrió Schelte Adams à Bolswert de San Ignacio de Loyola y San Francisco Javier juntos (h. 1633-1659) ${ }^{36}$. Igual que en ambas estampas, bajo la

\footnotetext{
32 Martínez, 2006: 187 [Tratado 9..$^{\circ}$.

${ }_{33}$ Martínez, 2006: 83. La doctora Manrique baraja como posible hipótesis que Martínez fuera alumno de Reni durante su estancia romana (Martínez, 2006: 79).

${ }^{34}$ González Hernández, 1981: 97. En el retablo mayor de la parroquial de Alagón (Zaragoza) se conserva una reproducción de esta obra, si bien no estamos en condiciones de atribuirla a Martínez (Pérez Sánchez, 1965: 190).

${ }^{35}$ Algunos autores consideran que Rubens pudo realizar dos pinturas de estos santos para la iglesia del Gesù que desaparecieron del templo a finales del siglo XVII. Véase Barrón García / Aramburu-Zabala Higuera, 2016: 33-37; y Vlieghe, 1973: 71-72 y fig. 39 [n. $\left.{ }^{\circ} 114\right]$.

${ }^{36}$ Este grabado puede localizarse en The British Museum: "San Francisco Javier y San Ignacio de Loyola". En: $<$ https://www.britishmuseum.org/collection/object/P_1891-0414-804> [31 de julio de 2020].
} 


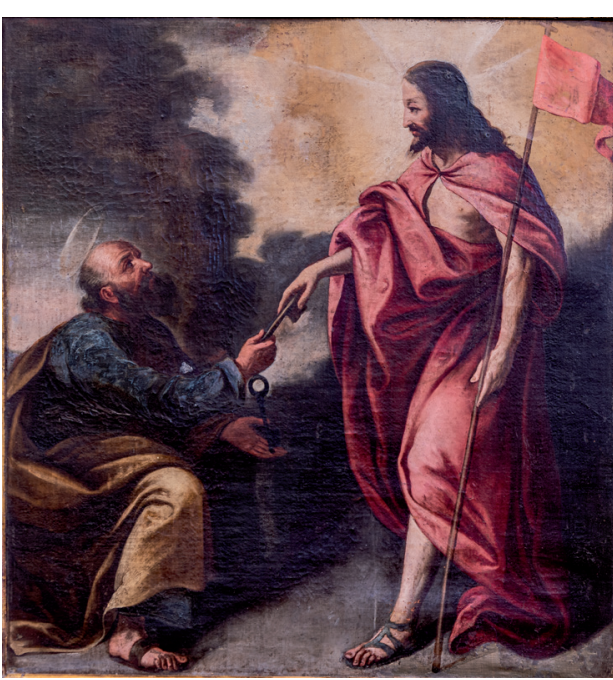

Fig. 6. Jusepe Martínez, Entrega de las llaves a San Pedro, 1653. Sabiñán, iglesia parroquial de San Pedro, retablo mayor (Fotog. Luisma García).

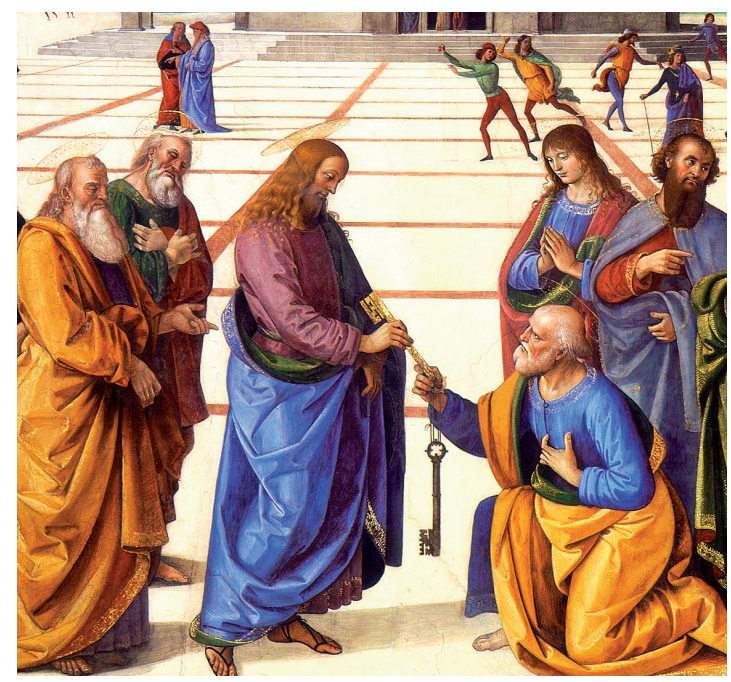

Fig. 7. Pietro Perugino, Entrega de las llaves a San Pedro, 1481-1482 (detalle). Roma, Capilla Sixtina, pared norte.

imagen del jesuita aparece una inscripción en letras capitales que lo identifica - S. FRANCISCVS XAVERIVS - . En esta ocasión, aunque no podemos descartar que Martínez hubiera contemplado in situ la pintura original de Rubens, parece más verosímil que se inspirara en el grabado.

Los otros dos lienzos del banco muestran sendos episodios de la vida del primer Papa, titular del templo. Como avanzamos, el tema representado en el lado del evangelio es la Entrega de las llaves a San Pedro [fig. 6]. El aragonés crea la escena de modo sencillo dado que sitúa a Cristo y al apóstol en un espacio libre de ambientación paisajística o arquitectónica en cuyo fondo únicamente destaca un celaje dorado detrás de la figura de Jesús. Este tratamiento compositivo es similar al que llevó a cabo tanto en la tela de San José con el Niño como en los santos de la predela del mencionado retablo mayor de La Almunia de Doña Godina ${ }^{37}$.

Además, representa al Mesías cubierto con una amplia túnica roja dejando el pecho, los brazos y las piernas desnudas y portando un estandarte carmesí, es decir, como Cristo resucitado triunfante sobre la muerte. De esta manera, el aragonés se aparta de los evangelios, pues según narra San Mateo (16: 18-19), este hecho sucedió inmediatamente antes del anuncio de Jesús de su propia muerte ${ }^{38}$.

De igual modo, Jusepe Martínez se aleja de la representación habitual de este tema, si bien la postura de ambos protagonistas, la forma de coger las llaves e incluso los rasgos de Cristo con la barba distribuida en dos guedejas, parecen evocar la pintura de idéntica iconografía que Perugino ejecutó entre 1481 y 1482 en la pared norte de la Capilla Sixtina [fig. 7].

El tipo masculino de perfil aquí reflejado es habitual en la obra de Martínez. Pese a ello, el apóstol recuerda al San Pedro penitente que José Ribera realizó para el duque de Osuna, virrey de Nápoles, en 1621 y que posiblemente se grabó ese mismo año ${ }^{39}$. A este respecto hay que señalar que no cabe ninguna duda de que el pintor zaragozano conocía la estampa ribereña dado que la reprodujo de manera literal en una de las telas del retablo de Uncastillo ${ }^{40}$.

En el extremo del banco del lado de la epístola se representa El sueño de San Pedro. Se trata de una escena poco habitual en el arte que Jusepe Martínez resolvió invirtiendo la composición de la pintura anterior y reiterando de forma prácticamente literal a Cristo y San Pedro. Entre ambos, en

\footnotetext{
37 Véanse las fotografías publicadas en Ansón Navarro, 2002: 51 y 60-69.

${ }^{38}$ No obstante, es preciso indicar que el grabado del mismo tema diseñado por Maarten de Vos y ejecutado por Hieronymus Wierix antes de 1611 muestra a Cristo resucitado. Véase Mauquoy-Hendrickx, 1978: 73 [n. ${ }^{\circ} 561$ ].

${ }_{39}$ Bellini / Carter Leach (eds.), 1983: 275 [n. ${ }^{\circ} 7$ (81)].

${ }^{40}$ Manrique Ara, 2002: 69.
} 


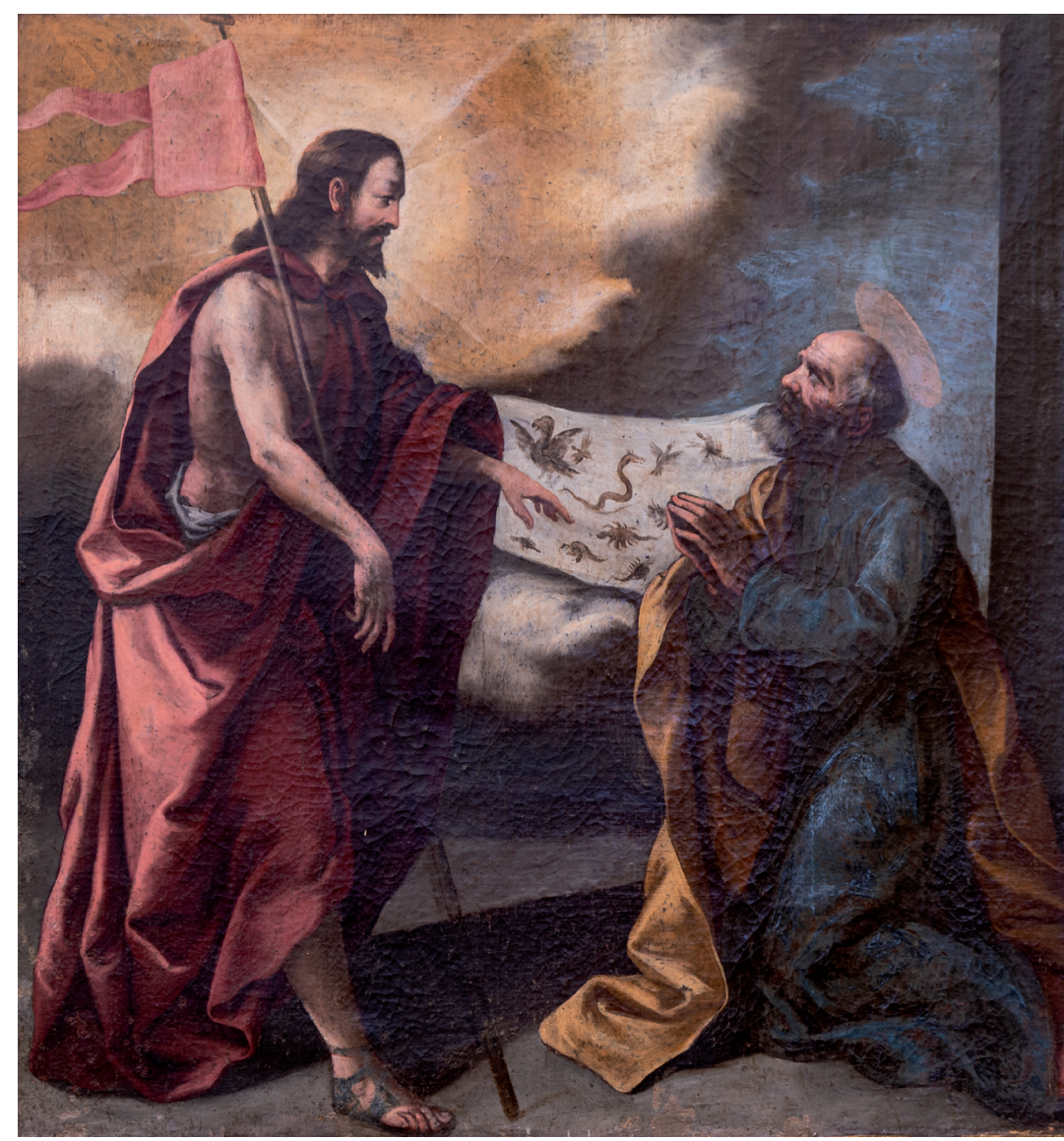

Fig. 8. Jusepe Martínez, El sueño de San Pedro, 1653. Sabiñán, iglesia parroquial de San Pedro, retablo mayor (Fotog. Luisma García).

segundo término, se distingue el lienzo que descendió del cielo donde aparecieron reflejados toda clase de animales, reptiles y aves, tal y como se narra en los Hechos de los Apóstoles (10: 9-16) [fig. 8]. En esta ocasión, la representación de Cristo como resucitado seguiría de modo más adecuado las Escrituras, pues este suceso tuvo lugar tras la muerte de Jesús. Sin embargo, su presencia en la escena parece más bien una licencia del artista, pues en el texto bíblico solo se cita su voz. De hecho, hay grabados, como el de Marteen de Vos (1585), donde el santo aparece solo, orando en un interior en el que se desarrolla la visión.

El lienzo que preside el cuerpo del retablo presenta a San Pedro en cátedra [fig. 9]. El primer apóstol, vestido de pontifical y tocado con la tiara papal, está sentado en su trono elevado sobre nubes. Levanta la mano derecha en actitud de bendecir, mientras que con la izquierda ase la férula rematada en una cruz de tres travesaños. A sus pies, arrodillados y, en primer término, se disponen dos obispos que se podrían identificar con dos Padres de la Iglesia — quizá San Ambrosio, a la izquierda, con las manos extendidas, y San Agustín, a la derecha, orante-. Flanqueando al Papa se encuentran San Pablo, en el lado del evangelio, portando la espada y el libro, y San Andrés, hermano de San Pedro, en el de la epístola, con el libro. Tras ellos, en el fondo, se distinguen cuatro personajes masculinos más, que identificamos, de izquierda a derecha, como San Jorge — con armadura y portando la bandera con su cruz - Santiago el Mayor — de peregrino-, San José — con la vara florida-, y un cuarto santo anciano y barbado cuyos atributos no se aprecian. En el tercio superior de la tela se abre un celaje de color azul y rosáceo del que emerge la paloma símbolo del Espíritu Santo rodeada por cuatro cabezas de querubines.

En esta pintura se percibe con nitidez la inclinación clasicista del zaragozano pues crea una composición simétrica, en la que las figuras se despliegan compensada y ordenadamente y, a la vez, piramidal, con San Pedro situado en la cúspide. 


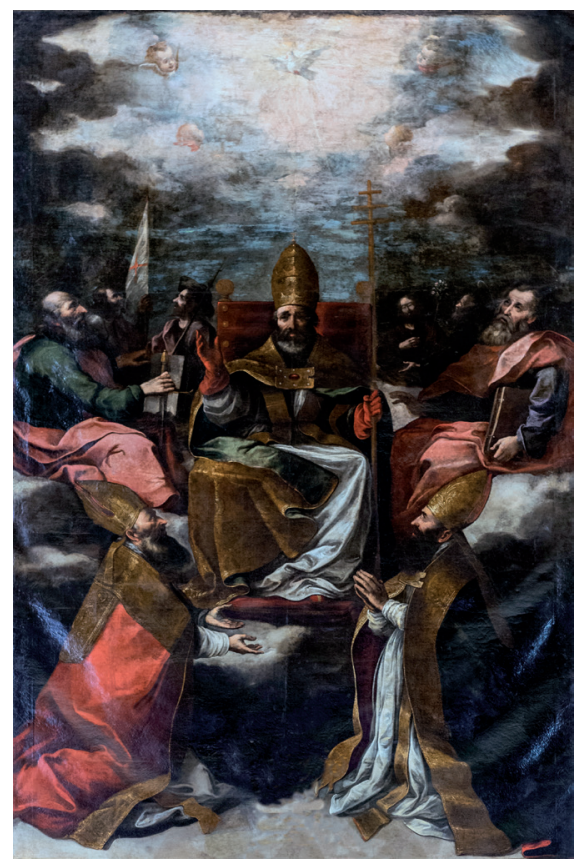

Fig. 9. Jusepe Martínez, San Pedro en cátedra, 1653. Sabiñán. Iglesia parroquial de San Pedro. Retablo mayor. Fotografía Luisma García.

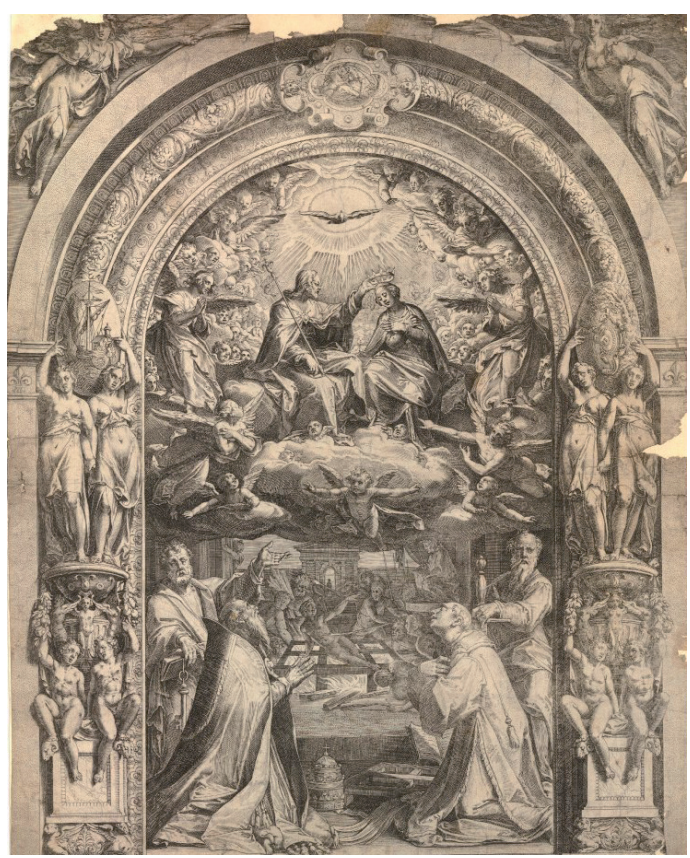

Fig. 10. Coronación de la Virgen con San Lorenzo, San Pablo, San Pedro y Sixto, grabado de Cornelis Cort según composición de Federico Zuccaro, 1576. (C) The Trustees of the British Museum, V,8.202.

En esta ocasión, es preciso advertir que el tema reflejado en este lienzo, pese a que cuenta con antecedentes pictóricos antiguos - como el de Masaccio (1424-1428) en la capilla Brancacci de la iglesia de Santa Maria del Carmine de Florencia-, resulta difícil de localizar antes de mediados del siglo XVII, pues la cátedra de San Pedro se revalorizó durante el pontificado de Alejandro VII (1655-1667) gracias a la gran máquina de bronce, estuco y mármoles que Gian Lorenzo Bernini ejecutó entre 1656 y 1666 para albergar la silla papal. Por esta razón, proponemos la posibilidad de que Martínez tomara como punto de partida una estampa con la representación de una escena que se caracterizase por la presencia de una multitud en torno a un personaje principal sedente. Para ello pudo inspirarse en grabados del episodio de Jesús entre los doctores o, quizá, en la Pentecostés donde María aparece rodeada de todos los apóstoles distribuidos de forma semejante a la tela de Sabiñán y, además, con la presencia sobre sus cabezas del Espíritu Santo en forma de paloma ${ }^{41}$.

No obstante, Jusepe Martínez creó una composición similar en el lienzo de La Virgen de Monserrat con los Santos Orencio, Paciencia y sus hijos San Lorenzo y San Orencio, obispo de Auch (h. 1645), de la basílica de San Lorenzo de Huesca, ya mencionado. Esta solución, además, podría ser una transposición de la Virgen en majestad a partir del estudio de la Pala Oddi (1503) de Rafael y de la Madonna de Monteluce (1505-2525) de Giulio Romano — ambas en la Pinacoteca Vaticana-, tal y como Martínez llevó a cabo en la tela principal (h. 1650) del retablo mayor de La Almunia de Doña Godina ${ }^{42}$. Tanto estas como la de Sabiñán recuerdan el tratamiento compositivo de la Coronación de la Virgen con San Lorenzo, San Pablo, San Pedro y Sixto que Federico Zuc-

${ }^{41}$ Esta misma circunstancia ha sido propuesta para la creación del relieve titular con este mismo tema iconográfico del retablo mayor de la iglesia de San Pedro de los Francos de Calatayud, confeccionado por Bernardo Ibáñez entre 1654 y 1658 aproximadamente (Carretero Calvo / Sánchez Ibáñez, 2019: 56-57).

${ }^{42}$ Como ha estudiado Manrique Ara, 2012: 300-306. 


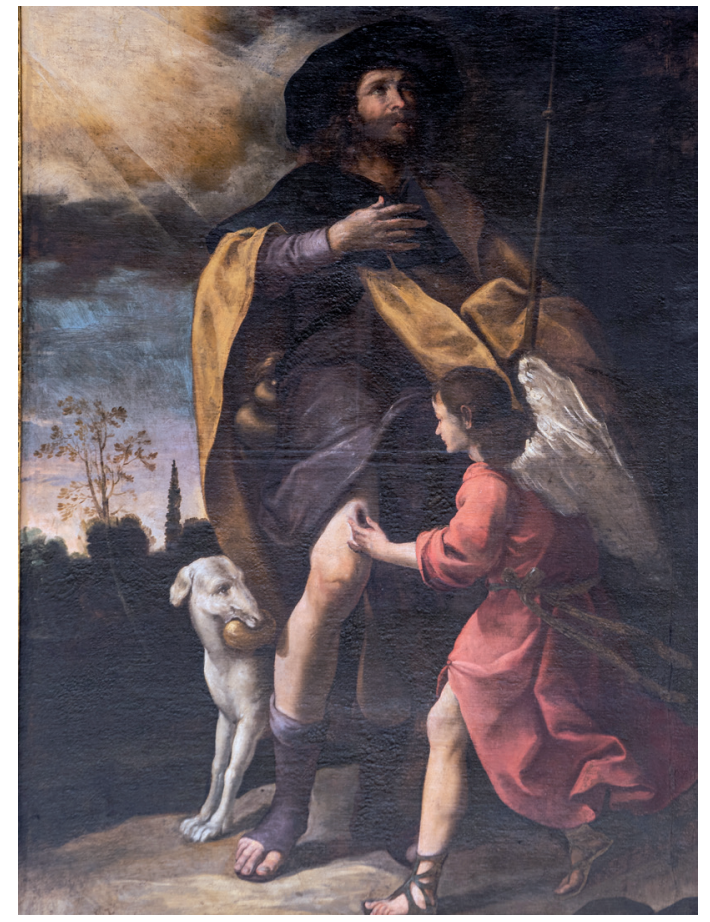

Fig. 11. Jusepe Martínez, San Roque, 1653. Sabiñán, iglesia parroquial de San Pedro, retablo mayor (Fotog. Luisma García).

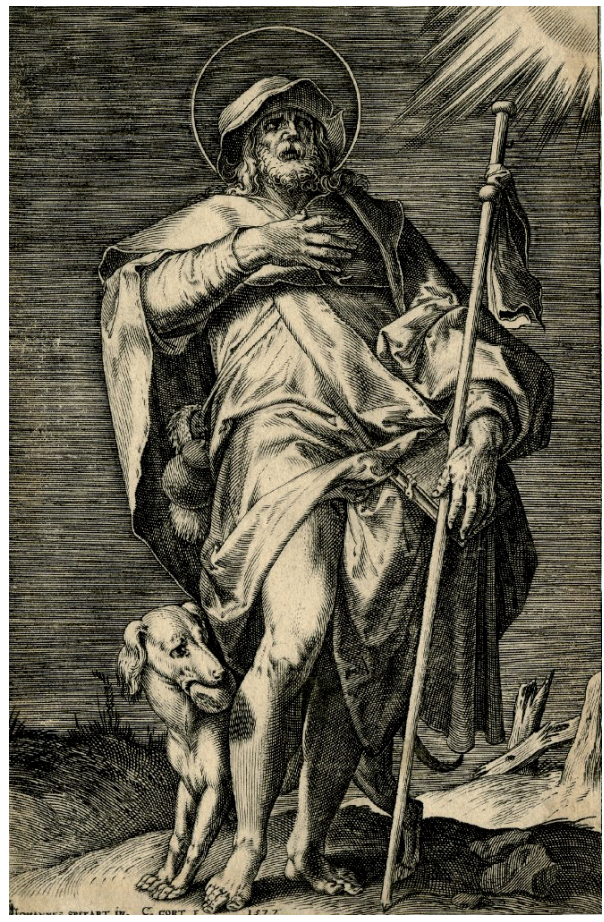

Fig. 12. San Roque, grabado de Cornelis Cort según composición de Hans Speckaert, 1577. (C) The Trustees of the British Museum, U,2.96.

caro llevó a cabo hacia 1569 para el ábside de la iglesia de San Lorenzo in Damaso de Roma ${ }^{43}$ y que fue incisa en 1576 por Cornelis Cort [fig. 10] ${ }^{44}$.

Al margen de todo lo anterior, la pintura que nos ocupa está tratada como una sacra conversazione a la italiana, pues Martínez ha representado una escena divina dotada de cierta naturalidad - de manera particular en las parejas de santos que "dialogan" en el fondo- $y$, al mismo tiempo, ha incluido personajes que sería difícil introducir coherentemente en la escena, dado que no responde a un pasaje real de la historia sagrada.

El ático está presidido por la representación de San Roque, como se recordará, patrón de la localidad [fig. 11]. Martínez se basó literalmente en el grabado del mismo tema de Cornelis Cort (1577) ${ }^{45}$, según composición de Hans Speckaert [fig. 12]. No obstante, incorporó la figura del ángel que, aunque no aparece en la estampa de Cort sí lo hace en otras, como en dos de Hieronymus Wierix: la primera publicada por Hans van Luyck y fechada antes de $1586^{46}$, y la segunda anterior a $1604^{47}$.

En definitiva, pese a que el documento es claro al respecto y no ofrece lugar a dudas de que Jusepe Martínez se desplazó a Sabiñán al menos en marzo de 1653, las características de las pinturas del retablo muestran los estilemas definitorios de su obra, sin que podamos descartar la participación de su taller ${ }^{48}$. En general, el dibujo es preciso y cuidado y sus personajes, de gran dignidad, creados con decoro y con una importante dosis de naturalismo en sus rostros, muestran expresividad y han sido dotados de actitudes serenas, en los que destacan sus delicadas manos.

\footnotetext{
43 Ostrow, 2005: 252.

${ }^{44}$ Strauss / Shimura (eds.), 1986: 165 [n. $\left.{ }^{\circ} 141-\mathrm{I}(147)\right]$.

${ }^{45}$ Strauss / Shimura (eds.), 1986: 170 [n. $\left.{ }^{\circ} 146-\mathrm{I}(152)\right]$.

${ }^{46}$ Mauquoy-Hendrickx, 1979: 169 [n. ${ }^{\circ} 1283$ ].

${ }^{47}$ Mauquoy-Hendrickx, 1979: 168 [n. ${ }^{\circ}$ 1280].

${ }^{48}$ Sobre los miembros conocidos de su taller consúltese Manrique Ara, 2002: 71-76.
} 
El colorido es bastante rico y luminoso, con gradaciones tonales, aunque detectamos un claroscuro moderado, sobre todo en la pintura titular. En ella también se aprecia cierta densidad atmosférica entre los personajes representados, rasgo diferenciador que, como no podía ser de otra manera, la convierten en la mejor del conjunto. Además, en realidad, esta tela es la única que responde a la total creatividad del artista debido a la gran deuda que, como hemos podido comprobar, el resto de sus pinturas mantienen con composiciones de grandes maestros - como Reni o Rubens - y grabadas.

En efecto, en sus Discursos practicables Jusepe Martínez recomienda la copia de estampas dentro de las primeras fases de aprendizaje de los jóvenes pintores. De hecho, en el tratado $1 .^{\circ}$ — titulado "Del dibujo y maneras de obrarlo con buena imitación"— advertía al principiante que, una vez "acabado este ejercicio de las estampas, que se vea ya dueño de la imitación bien ajustada, acudirá a valerse de dibujos de hombres diestros y bien acabados y con consejo de su maestro, que sin este irá mal guiado"49, dejando, al menos en teoría, de usarlas.

Un poco más adelante, en el brevísimo tratado $6 .^{\circ}$ - "De la unión"- vuelve a mencionar la utilidad de esta práctica por el aprendiz para crear la composición de la obra asegurando que

para aviso y ejemplar de esta doctrina valdrase nuestro estudioso de estampas de excelentísimos maestros, que estas tales le darán el suficiente desengaño, aunque algunos fantásticos y soberbios, como ignorantes de toda verdad, han vituperado este modo de estudio viendo claramente que los antiguos han sido con sus ejemplares el adelantamiento de los modernos. De modo que, a no ver sus obras, quedaran muy ignorantes, y así, todo estudioso se prevenga para sujetarse al maestro, porque el que no lo hace así no puede ser buen discípulo ${ }^{50}$.

Insiste en ello en su tratado 9. - “Del historiar con propiedad" — cuando recomienda que

No sea tan confiado el estudioso que le parezca que lo puede alcanzar todo por sí solo; que para su desengaño le propondré muchos ejemplares de los más insignes maestros, como Miguel Ángel, Polidoro y Giulio Romano, que se valieron de cosas muy públicas, de estatuas, medio relieves antiguos de Roma, sirviéndose de ellos con tal gracia y arte que los superaron. Para valerse del trabajo ajeno no se requiere menos gracia que para la invención propia, porque esto no se toma más sobre lo visto, añadiendo cierta bizarría que da mayor realce y es permitido en todo género de profesión ${ }^{51}$.

Sin embargo, el estudio detenido de los lienzos del retablo de Sabiñán ha revelado que el aragonés se servía de los grabados más de lo que, en principio, aconsejaba ${ }^{52}$, aprovechando —quizá- la circunstancia, denunciada más adelante por Antonio Palomino, de que "el vulgo no distingue entre las cosas, que son copiadas o inventadas, sino que se deja llevar de aquello que parece bien"53. No obstante, este procedimiento fue seguido por tantos pintores a lo largo de los siglos de la Edad Moderna, incluido Daniel Martínez, su padre ${ }^{54}$, que resultaría prolijo recordarlos aquí ${ }^{55}$. De todos modos, no debemos olvidar que en ocasiones eran los propios comitentes quienes imponían la reproducción de determinados grabados a los artistas, práctica recogida por los tratadistas de la época ${ }^{56}$.

Sin estar en disposición de descartar esta última consideración, lo que parece fuera de toda duda es que para entonces Martínez contaba con más encargos de los que podía asumir. Esta circunstancia podría haberle obligado a poner en marcha su taller para, partiendo de composiciones grabadas, crear algunas de estas obras. Como apuntamos, a partir de su nombramiento como pintor

49 Martínez, 2006: 160 [tratado $1^{\circ}{ }^{\circ}$ ].

${ }^{50}$ Martínez, 2006: 177-178 [tratado 6. ${ }^{\circ}$ ].

${ }^{51}$ Martínez, 2006: 210-211 [tratado 9. ${ }^{\circ}$ ].

52 Acerca de las recomendaciones de otros tratadistas sobre esta práctica y del concepto de original y copia en el siglo XVII véase Navarrete Prieto, 1998: 25-40.

${ }_{53}$ Recogida en Navarrete Prieto, 1998: 26.

${ }^{54}$ Véase Criado Mainar, 2013b: 289-300; y Morte García, 2019: 409-411.

${ }_{55}$ Pese a ello, no queremos dejar de mencionar, aunque sea brevemente, el caso paradigmático del italiano Pietro Morone (1515/1520-1577) que llegó a tierras aragonesas cargado de apuntes, dibujos y grabados que incorporó en sus propias composiciones, haciendo arribar a Aragón los ecos de algunas de las obras más importantes del Renacimiento romano. Véase Criado Mainar / Cantos Martínez, 2020.

${ }^{56}$ Navarrete Prieto, 1998: 32-40. 
ad honorem del rey en 1644 sus contratos aumentaron, siendo los años finales de la década de 1640 y la siguiente la época de mayor auge ${ }^{57}$. De hecho, a los lienzos para los retablos mayores de Uncastillo y La Almunia de Doña Godina y para el de la capilla de la Virgen Blanca de la catedral zaragozana, ya mencionados, hay que añadir las telas para el mueble principal de la iglesia del convento de agustinos descalzos, capitulado en enero de 1646; las pinturas para la capilla de San Luis Gonzaga de la iglesia de la Compañía de Jesús de Zaragoza, en ejecución en septiembre de 1652; la concordia, firmada en febrero de 1653 pero finalmente frustrada, de la realización de cuatro óleos para la capilla de San José de la cofradía zaragozana de carpinteros, establecida en la iglesia del monasterio de Santa Engracia; o tres cuadros para la villa de Beceite (Teruel), concertados en 1657 y entregados al año siguiente ${ }^{58}$. A esta nómina debemos incorporar ahora las pinturas del retablo mayor de Sabiñán (1653).

\section{Jusepe Martínez en Sabiñán}

El último interrogante que intentamos disipar es cómo la parroquia y el concejo sabiñaneros llegaron a considerar a Jusepe Martínez como una opción para llevar a cabo las pinturas del retablo mayor de la iglesia de San Pedro.

Como vimos, el pintor se encontraba en la localidad bilbilitana el 25 de marzo de 1653, día en el que llevaba hasta allí sus lienzos para que fueran acomodados en el mueble litúrgico. A comienzos de ese mismo mes, el día 9, Martínez estaba en la capital aragonesa nombrando como su procurador a su hijo para cobrar 55 libras jaquesas de parte de Jerónima de Sola que recibió veinticuatro horas más tarde ${ }^{59}$. La siguiente noticia documental, fechada el 23 de mayo, sitúa al artista ya en Zaragoza transfiriendo a Miguel Pérez de Esco una cantidad económica que le adeudaba $^{60}$. En vista de ello podemos determinar que, en todo caso, la visita a Sabiñán debió ser muy breve. No obstante, resulta interesante advertir que por aquellos años - en concreto, entre marzo de 1652 y abril de 1653 - Zaragoza estaba padeciendo la mayor crisis de peste del siglo XVII, por lo que, quizá, Jusepe no dudó en abandonar la ciudad para trasladarse a atender este trabajo, pues la Comunidad de Calatayud, en esta ocasión, quedó libre de la epidemia ${ }^{61}$.

A esta hipótesis debemos añadir que, según Gracián Gasca, hubo una familia de infanzones de apellido Martínez, oriunda de Ariza (Zaragoza), instalada en Sabiñán desde el siglo XVI. Al menos dos miembros de esta estirpe fueron canónigos de la Seo de Zaragoza: José Martínez Arisco († 1697) — que ha sido identificado con José Martínez Asensio- y su sobrino José Martínez Saldaña $(\dagger 1735)^{62}$. De ambos se conservan retratos en la parroquial de San Pedro ${ }^{63}$. Aunque se desconoce el año de nacimiento del primero y sabemos que no tomó posesión de una canonjía en la catedral zaragozana hasta el 3 de enero de $1662^{64}$, quizá José Martínez Arisco fue quien estableció el contacto con el pintor, pues para 1653 este ya trabajaba en la Seo.

${ }^{57}$ Como se pone de relieve en Ansón Navarro, 2002: 8-9; y en Manrique Ara, 2002: 74.

58 Estas obras, o desaparecidas o en paradero desconocido, están documentadas en González Hernández, 1981: 167 201 [docs. núms. 61, 62, 66, 68, 70, 74, 75, 77, 78, 79, 81, 83, 88, 89, 93, 95, 96, 97, 98, 110 y 112].

${ }^{59}$ González Hernández, 1981: 188-189 [docs. núms. 90 y 91].

${ }^{60}$ González Hernández, 1981: 189 [doc. n. ${ }^{\circ}$ 92].

${ }^{61}$ Maiso González, 1982: 52. De hecho, una de las reacciones sociales más frecuentes frente a la peste fue la huida, como se pone de relieve en Maiso González, 1982: 108-111.

${ }^{62}$ Gracián Gasca, 2013: 19. Véase, asimismo, Tobajas Gallego, 2019: s. p.

${ }^{63}$ Una imagen del retrato del canónigo José Martínez Asensio, en mal estado de conservación, se encuentra en https://sites.google.com/view/museosabinan/p\%C3\%Algina-principal/museo-de-sabi\%C3\%B1\%C3\%Aln/personajes\#h.p_cixnMe7PqqIL [10 de julio de 2020].

${ }^{64}$ La única información recogida por José Ypas acerca de este canónigo es que "por muerte del señor D. Juan Mancebo nombró el Papa para su prevenda a D. Joseph Martinez de Arisco, cuia posesion tomo el día 3 del mes de Enero del año 1662. Diola a coadjutoria en 19 de Mayo del año 1690 en favor de su sobrino D. Joseph Martinez Saldaña; pero tuvola en propiedad hasta 18 de Febrero de 1697, en que murió. Dispuso su entierro en secreto, y el libro de Gestis Capítuli no dice donde". En Catalogo chronologico de los deanes, dignidades, y canonigos del Santo Templo del Salvador de Zaragoza desde la Bulla de Secularizado hasta la de Union. Hizole el Racionero Joseph Ypas Secretario del Ilustrisimo Cabildo. Año 1786, Biblioteca Capitular de la Seo de Zaragoza, sign. 11-14, ff. 54-54 v., n. ${ }^{\circ} 160$. 
No obstante, desconocemos si los Martínez de Sabiñán mantenían algún tipo de parentesco con Jusepe Martínez. Aunque su padre era de origen belga, en el contrato de aprendizaje que firmó con el pintor Felices de Cáceres en Zaragoza el 30 de noviembre de 1575 asegura llamarse "Daniel Martínez, natural de la ciudad de Amborg del Reyno de Flandes" ${ }^{65}$, por lo que cabe la posibilidad de que fuera hijo de, al menos, padre español y, por qué no, de ascendencia aragonesa.

\section{Conclusiones}

Como ya ha sido puesto de manifiesto, los años italianos de Jusepe Martínez fueron decisivos no solo para redactar cincuenta años más tarde su tratado artístico, sino para su producción pictórica $^{66}$. Gracias a su propio testimonio sabemos que se formó junto a Guido Reni y Domenichino, imbuyéndose de las composiciones italianas que más tarde plasmó en varias de sus obras. De hecho, los lienzos que hemos presentado en este texto conforman un muestrario de ese bagaje cultural martinesco (Reni, Rubens, Rafael, Perugio, etc.), constituyendo un magnífico ejemplo de la influencia del arte italiano en la pintura aragonesa. No obstante, también reflejan la práctica, habitual por otra parte, de emplear estampas para la creación de nuevas obras. Entre ellas, los grabados de Cornelis Cort (h. 1533-1578) ${ }^{67}$, holandés fallecido en Roma, destacan en su haber.

Sin descartar la participación de miembros de su taller, las pinturas de Sabiñán exhiben las características definitorias de la producción de Martínez situada a caballo entre el clasicismo reniano y el naturalismo ${ }^{68}$, tal y como ha quedado patente en el lienzo titular.

Asimismo, el pintor se muestra en estas obras sobrio en detalles que pudieran resultar superfluos para la compresión del mensaje religioso, y muy preocupado por el decoro, en sintonía con los preceptos de la Iglesia contrarreformista. No en vano, su estancia romana le permitió conocer de primera mano las características del arte que se estaba desarrollando en aquellos momentos en la caput mundi del catolicismo y que arribarían a tierras aragonesas en gran medida gracias a él.

Además, como se ha podido apreciar en las escenas de la vida de San Pedro acomodadas en el banco, es un artista que huye de las maneras acabadas y minuciosas. Esta práctica frecuente le conllevó alguna que otra crítica, como se pudo corroborar documentalmente en la recepción de las pinturas del retablo de Uncastillo, que debieron ser retocadas por Francisco Navarro, dorador del mueble, entre 1667 y $1668^{69}$. En este caso, la restauración de dicho retablo, llevada a cabo gracias al Plan Bienal de Restauración de Bienes Muebles 2000-2001 promocionada por la Diputación Provincial de Zaragoza, reveló la presencia de al menos dos manos en la factura de los lienzos ${ }^{70}$.

En definitiva, nos encontramos ante un conjunto de pinturas bien documentado que transmite a la perfección los estilemas de la obra de Jusepe Martínez en un momento en el que, aunque ya había alcanzado el cénit de su carrera, las referencias artísticas italianas asimiladas en sus años de formación siguen estando muy presentes.

Apéndice documental

Doc. . $^{\circ} 1$

1652, diciembre, 20

Sabiñán

El dorador Juan Ortiz y Baraiz, habitante en la villa de Brea, reconoce tener en comanda de la iglesia parroquial de San Pedro de Sabiñán 8.000 sueldos jaqueses.

Archivo Histórico de Protocolos Notariales de Calatayud [A.H.P.C.], Miguel García Guerrero, notario de Sabiñán, libro 1437, 1652, f. 129.

\footnotetext{
${ }^{65}$ Criado Mainar, 2013b: 300 [doc. n. ${ }^{\circ} 1$ ].

${ }_{66}$ Manrique Ara, 2000: 81.

67 También se sirve de al menos un grabado de Cort — la Epifanía (1567) a partir de un dibujo de Giulio Clovio- en la obra de Uncastillo (Manrique Ara, 2002: 102-103).

${ }^{68}$ Ansón Navarro, 2002: 35.

69 Según queda estipulado con suma claridad en el contrato de dorado publicado en Manrique Ara, 2002: 167-173 [doc. n. ${ }^{\circ}$ XXIII, esp. § 2].

${ }^{70}$ Manrique Ara, 2002: 71.
} 
/f. 129/ [Al margen: Comanda].

Die vigesimo mensis decembris. Anno MDCLII. In loco de Saviñan.

Eodem die et loco, yo, Juan Ortiz y Baraiz, dorador, havitante en la villa de Brea, de grado, et cetera, reconozco tener en comanda, et cetera, del mayordomo que es y por tiempo sera de la iglesia parrochial de San Pedro del lugar de Saviñan y de los suyos, son a saver ocho mil sueldos jaqueses, los quales al presente dia de oy en mi poder de contado aviso encomandado y aquellos de vos en comanda y deposito otorgamos haver recibido.

[A continuación, cláusulas de escatocolo y consignación de dos testigos: Pedro Terrer y Simon Martinez menor, labradores, habitantes en Sabiñán.]

[Suscripciones autógrafas:

Yo, Juan Ortiz y Baraiz, asi lo otorgo.

Yo, Pedro Terrer, soy testigo de los sobredicho y me firmo por mi contestigo que dixo no sabia escribir.]

Attesto que no hay que salvar, et cetera.

Finis anno Domini 1652.

Doc. n. ${ }^{\circ} 2$

1653, marzo, 25

Sabiñán

El pintor Jusepe Martínez, domiciliado en Zaragoza y hallado en Sabiñán, otorga haber recibido de la iglesia parroquial de San Pedro y del concejo de Sabiñán 5.000 sueldos jaqueses y 12 arrobas de aceite "por la pintura del retablo mayor de dicha iglesia" y otros 800 sueldos más "por aber benido a concertar la obra i traella".

A.H.P.C., Miguel García Guerrero, notario de Sabiñán, libro 1438, 1653, f. 30 v.

/f. 30 v./ Die vigesimo quinto mensis marcii anno MDCLIII in loco de Saviñan.

[Al margen: Apoca].

Eodem die et loco.

Yo, Jusepe Martinez, pintor, domiciliado en la ciudad de Caragoza y al presente allado en el lugar de Saviñan, de grado, et cetera, otorgo de los vicario, beneficiados y capitulo de la iglesia parrochial del señor San Pedro del lugar de Saviñan, y de los jurados y concejo del dicho lugar, son a saver, a una parte cinco mil sueldos jaqueses y doce arrobas poco mas de aceite por otros tantos me an de por la pintura del retablo mayor de dicha iglessia con inclusion de qualesquiere otras apocas ante contadas y a otra parte ochocientos sueldos jaqueses que me an dado por sustento [y] trebajos subenidos por aber benido a concertar la obra i traella. Y por la berdat renunciando, et cetera, otorgo la presente apoca, et cetera. Fiat large.

Testigos Miguel Gascon y mossen Augustin de Villalva, presbiteros, havitatoris Saviñan.

[Suscripciones autógrafas: Yo, Jusepe Martinez, otorgo lo arriba dicho.

Yo, mossen Miguel Gascon, soy testigo de lo sobre dicho.

Yo, mossen Augustin Villalba, soy testigo de lo sobredicho].

Atento que no hay que salvar. Et cetera.

\section{BIBLIOGRAFÍA}

Ansón Navarro, Arturo (1987): "El gremio de doradores de Zaragoza (1675-1820)". En: Homenaje a don Federico Balaguer Sánchez. Huesca: Instituto de Estudios Altoaragoneses, pp. 485-511.

Ansón Navarro, Arturo (1989): "Un cuadro inédito de Jusepe Martínez en la basílica de San Lorenzo de Huesca: 'La Virgen de Monserrat con los Santos Orencio, Paciencia y sus hijos San Lorenzo y San Orencio, obispo de Auch"”. En: Aragonia Sacra, IV, Zaragoza, pp. 7-11.

Ansón Navarro, Arturo (2002): "El Retablo Mayor de la Iglesia de Ntra. Sra. de La Asunción de La Almunia de Doña Godina y las pinturas de Jusepe Martínez". En: Ador, 6, monográfico especial, La Almunia de Doña Godina.

Barrón García, Aurelio Á. / Aramburu-Zabala Higuera, Miguel Ángel (2016): "Pinturas del taller y círculo de Rubens legadas en Logroño en 1622". En: Ars Bilduma, 6, Vitoria, pp. 23-41.

Bellini, Paolo / Carter Leach, Mark (eds.) (1983): The Illustrated Bartsch. Italian masters of the seventeenth century. Nueva York: Abaris Book, t. 44.

Boloqui Larraya, Belén (1983): Escultura zaragozana en la época de los Ramírez, 1710-1780. Granada: Ministerio de Cultura, 2 vols.

Carreras, José M. / Núñez, Mercedes / Ripollés, Encarna (2010): Retablo mayor de la iglesia de Nuestra Señora de la Asunción. La Almunia de Doña Godina. Informe de la restauración. Zaragoza: Ayuntamiento de La Almunia de Doña Godina.

Carretero Calvo, Rebeca (2007): "Estudio histórico y artístico". En: El retablo mayor de la iglesia parroquial de Fuentes de Jiloca. Zaragoza: Diputación Provincial de Zaragoza, pp. 29-89.

Carretero Calvo, Rebeca / Sánchez Ibáñez, Ana (2019): El retablo mayor de San Pedro de los Francos de Calatayud. Calatayud: Centro de Estudios Bilbilitanos de la Institución «Fernando el Católico». 
Carretero Calvo, Rebeca (2020): "Santo para los altares pero no para Roma: La devoción a San Pedro Arbués y el clero aragonés a finales del siglo XVII". En: Serrano Martín, Eliseo (coord.): Elites políticas y religiosas, devociones y santos (siglos XVI-XVIII). Zaragoza: Institución «Fernando el Católico», pp. 239-283.

Cortés Perruca, José Luis (2019): Brea de Aragón a través de su historia y patrimonio. Brea de Aragón: Ayuntamiento de Brea de Aragón.

Costa Florencia, Javier (2017): Torrijo de la Cañada. Historia y patrimonio artístico. Zaragoza: Institución «Fernando el Católico».

Criado Mainar, Jesús (2011): "El retablo mayor de la Colegiata de Santa María y la consolidación de la escultura romanista bilbilitana”. En: Actas del VIII Encuentro de Estudios Bilbilitanos. Calatayud: Centro de Estudios Bilbilitanos de la Institución «Fernando el Católico», t. I, pp. 13-45.

Criado Mainar, Jesús (2013a): La escultura romanista en la Comarca de la Comunidad de Calatayudy su área de influencia. 1589-1639. Calatayud: Centro de Estudios Bilbilitanos de la Institución «Fernando el Católico».

Criado Mainar, Jesús (2013b): "Daniel Martínez en el taller de Felices de Cáceres y la renovación en clave flamenca de la pintura zaragozana en la década de 1570". En: Álvaro Zamora, M. Isabel / Lomba Serrano, Concepción / Pano Gracia, José Luis (coords.): Estudios de Historia del Arte. Libro homenaje a Gonzalo M. Borrás Gualis. Zaragoza: Institución «Fernando el Católico», pp. 289-300.

Criado Mainar, Jesús (2014): "Los bustos relicarios femeninos en Aragón 1406-1567”. En: García Herrero, M." del Carmen / Pérez Galán, Cristina (coords.): Mujeres de la Edad Media: actividades políticas, socioeconómicas y culturales. Zaragoza: Institución «Fernando el Católico», pp. 341-368.

Criado Mainar, Jesús / Cantos Martínez, Olga (2020): “Estudio histórico-artístico”. En: Cantos Martínez, Olga (coord.): El retablo mayor de San Miguel arcángel en Ibdes. Estudio e intervención. Madrid: Ministerio de Cultura y Deporte.

González Asenjo, Elvira (2005): Don Juan José de Austria y las artes (1629-1679). Madrid: Fundación de Apoyo a la Historia del Arte Hispánico.

González Asenjo, Elvira (2019): “Juan José de Austria: afición, práctica y 'deleite’ por la ciencia y las artes”. En: Cuadernos de Historia Moderna, 44, 2, Madrid, pp. 481-509.

González Hernández, Vicente (1981): Jusepe Martínez (1600-1682). Zaragoza: Museo e Instituto de Humanidades «Camón Aznar».

Gracián Gasca, José (2013): Notas para la historia de Sabiñán. Precedidas de breves noticias de la institución, gobierno e historia de la Comunidad de Calatayud (1919). Texto revisado y publicado por Tobajas Gallego, Francisco. Sabiñán: Asociación Cultural "Sabinius Sabinianus".

Lacarta Aparicio, Ana / García-Aráez, Javier / Menéndez Zapata, Lorena (2010): Investigación y patrimonio en la provincia de Zaragoza. II. Zaragoza: Escuela-Taller «Blasco de Grañén» de la Diputación de Zaragoza.

Lozano López, Juan Carlos (2010): "La pintura barroca en la Seo de Zaragoza: viejos problemas, nuevas visiones". En: Lacarra Ducay, M. ${ }^{\text {a }}$ Carmen (coord.): El barroco en las catedrales españolas. Zaragoza: Institución «Fernando el Católico», pp. 65-100.

Maiso González, Jesús (1982): La peste aragonesa de 1648 a 1654. Zaragoza: Departamento de Historia Moderna de la Universidad de Zaragoza.

Manrique Ara, M. ${ }^{a}$ Elena (2000): Jusepe Martínez, un pintor zaragozano en la Roma del Seicento. Zaragoza: Institución «Fernando el Católico».

Manrique Ara, M. ${ }^{a}$ Elena (2002): Jusepe Martínez y el Retablo Mayor de Santa María de Uncastillo. Estudio históricoartístico y de restauración. Zaragoza: Diputación de Zaragoza.

Manrique Ara, M. a Elena (2012): “La Asunción de la Virgen”. En: Calvo Ruata, José Ignacio (coord.): Joyas de un Patrimonio IV. Estudios. Zaragoza: Diputación Provincial de Zaragoza, pp. 300-306.

Martínez, Jusepe (2006): Discursos practicables del nobilísimo arte de la pintura. Edición, introducción y notas de Manrique Ara, M. ${ }^{a}$ Elena. Madrid: Cátedra.

Martínez, Jusepe (2008): Discursos practicables del nobilísimo arte de la pintura. Edición, introducción y notas de Man-

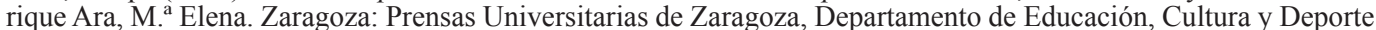
del Gobierno de Aragón, Instituto de Estudios Altoaragoneses e Instituto de Estudios Turolenses.

Mauquoy-Hendrickx, Marie (1978-1979): Les estampes des Wierix conservées au cabinet des estampes de la Bibliothèque Royale Albert I. Bruselas: Bibliothèque Royale Albert I, 2 vols.

Morte García, Carmen (2019): "Que se haga al modo y manera de [...]: Copy and Interpretation in the Visual Arts in Aragón during the 16th Century". En: Bellavitis, Maddalena (ed.): Making Copies in European Art 1400-1600. Shifting Tastes, Modes of Transmission, and Changing Contexts. Leiden y Boston: Brill, pp. 387-426.

Navarrete Prieto, Benito (1998): La pintura andaluza del siglo XVII y sus fuentes grabadas. Madrid: Fundación de Apoyo a la Historia del Arte Hispánico.

Ostrow, Steven F. (2005): "The Counter-Reformation and the end of the century". En: Hall, Marcia B. (ed.): Artistic centers of the Italian Renaissance. Rome. Nueva York: Cambridge University Press, pp. 246-320.

Pérez Sánchez, Alfonso E. (1965): Pintura italiana del siglo XVII en España. Madrid: Fundación Valdecilla.

Roy Lozano, Araceli (2006): "Las artes en Aragón en el siglo XVII según el Archivo de Protocolos Notariales de Zaragoza. De 1625 a 1627”. En: Bruñén Ibáñez, Ana Isabel / Julve Larraz, Luis / Velasco de la Peña, Esperanza (coords. y eds.): Las artes en Aragón en el siglo XVII según el archivo de Protocolos Notariales de Zaragoza. De 1613 a 1696. Zaragoza: Institución «Fernando el Católico», t. V.

Rubio Semper, Agustín (1980): Estudio documental de las artes en la Comunidad de Calatayud durante el siglo XVII. Calatayud: Centro de Estudios Bilbilitanos de la Institución «Fernando el Católico».

Strauss, Walter S. / Shimura, Tomoko (eds.) (1986): The Illustrated Bartsch. Netherlandish Artists. Cornelis Cort. Nueva York: Abaris Books, t. 52.

Tobajas Gallego, Francisco (2019): “La capilla de la Virgen del Rosario [de Sabiñán]”. En: Enebro, 102, Sabiñán, s. p. Vlieghe, Hans (1973): “Saints”. En: Corpus Rubenianum Ludwig Burchard, 8. Londres y Nueva York: Phaidon, vol. II. 